\title{
INDIVIDUALIZATION, ENVIRONMENT AND CHRISTIANITY (CHALLENGES AND VISIONS OF NEW ETHICS)
}

The article reacts to new challenges in the phenomenon of individualization that are accompanied with the extreme scientific and technological growth. It focuses on controversial issues of civilization and traditional ethics: anthropocentrism, consumerism, individualism, and scientism. It stands for new ethics that would connect the good of man with the good of the environment.

Key words: individualization, anthropocentrism, civilization, asceticism.

\section{Individualization - Phenomenon of Postmodern Society}

Individualization is a distinctive phenomenon of the postmodern society. In present understanding the individualization means: "The act or process of individuating, especially the process by which social individuals become differentiated one from the other" [1, p. 565]. Nowadays, the individualization is accompanied with many obvious issues: human rights, respect to minor cultures and lifestyles; in information technology with using notebooks or communicating via social networks and mobile phones; its influence can be seen in consumers' demands for individual packaging of products; individual approach is required in human relationships; education system tries to include handicapped learners or learners with various disabilities; the offer of the internet banking, or such a negligible thing like plastic bags at supermarkets for each customer. The postmodern period put the individual on a pedestal. What was appointed to be used only by the elite in the past nowadays can be used by the whole population. Democratization has enabled an ordinary man to make use of all comfort a modern way of life offers. However, such approach brings many problems. Experts warn of destruction of nature and the environment, technocracy, worsening of human relations, lack of communication, disintegration of traditional values, egocentrism, consumerism, the insuperable gap between the rich countries of the Western region and developing countries of the Third World. As it is clearly visible many predictions have already come true. The terms 'crisis' and 'depression' have become natural parts of everyday language. However, once the level of individualization has reached its peak, there is no way to step backwards and let the man disappear in the crowd.

\section{Anthropocentric Orientation of Western Civilization}

The individualization is closely connected with the anthropocentric character of Western intellectual tradition, the phenomenon that has been glorified as well as damned. The anthropocentrism placed the man's well-being into the centre of the universe: "The essential feature of the anthropocentric dimension of the cosmological domain is the belief that humans are separate from and ethically superior to the rest of nature. As a result, humans consider themselves to be rightfully, the masters of nature subduing it for their own instrumental purposes" [2, §5]. To justify this, humans use various explanations based on ontological and epistemological reasons. The anthropocentrism developed in several lines throughout the Western culture: Greek tradition, Christian religion and the scientific development.

As long as the civilization had not been affected by the enormous growth in technocracy, industrialization and their invasive interference into the nature, anthropocentrism stood for cognitive, ontological, moral superiority of a human being over the material reality. The basis lies in special qualities of the man. The ancient Greeks stressed the reason (logos) as the main distinctive feature. Socrates pointed out at 'daimonion' that represented an inner voice of which he said: "This sign I have had ever since I was a child. The sign is a voice which comes to me and always forbids me to do something which I am going to do, but never commands me to do anything (...)" $[3, \S 34]$. Worth mentioning could be the term 'telos' that is the Greek word used in Bible for perfection as it stands for the Greek equivalent of the Latin word 'perfectio'. The term was highly used in the Ancient philosophy in the meaning of

\footnotetext{
* Zuzana Zilova

Faculty of Humanities, University of Zilina, Slovakia, E-mail: zuzana.zilova@fpv.uniza.sk
} 
purpose, goal, end. Aristotle comments: "There is some end of the things we do, which we desire for its own sake" $[4, \S 1]$. The European tradition inherited the idea that each thing had an inner plan, intention, or a fixed place in the hierarchy of being that determined its position and role in the universe. Thus, the teleological organization of the world had raised the man on the top of the pyramid for thousands of years.

Another lineage of anthropocentrism develops in Christian tradition which based human prominence on the creation of the man in the 'Image of God' [5]. Due to this the man was endowed with such qualities like: intellect, consciousness, freedom, soul. As these qualities are analogous to perfect qualities of God the man is a "free and intelligent subject with the capacity to know God, truth and goodness" [6, § 4]. Moreover, by words: "let them have dominion over the fish of the sea, over the birds, of the air, and over the cattle, over all the earth and over every creeping thing that creeps on the earth" [5, Gen., 26], the man was authorized to act on behalf of God. Unfortunately, humanity may have forgotten the other side of the biblical command requiring the man to take care of the Earth and subsequent responsibility for its well-being. Following the Christian tradition, the ideas of environmentalism and ecology can be traced in spirituality of the Italian Catholic friar Francis of Assisi - a patron saint of animals. According to his rule: "we should respect all creatures, animate or inanimate, which bear the imprint of the Most High and we should strive to move from the temptation of exploiting creation to the Franciscan order of universal kinship" [7, 18].

The last lineage of anthropocentrism leads via the scientific and technological development. Its primary purpose was focused on recognition of laws of nature following the improvement of life and its conditions in order to support human well-being. Francis Bacon appeared to be a pioneer when stating that 'scientia potentia est', ergo knowledge is power [8] opening the way for the incredible development in science and technology. In this meaning anthropocentrism follows the idea that the man's greatness lies in capability of knowing, applying and even interfering the natural world and the use of the knowledge for human benefit. An important element could be seen in demystification of nature which supported its instrumental role and approved the manipulation with the environment. Finally, the influence of science has appeared pretty ambiguous. Although it has improved the life of an individual and enriched human existence by many astonishing inventions; its aggressive expansion has threatened other parts of reality. Thus, anthropocentrism is a best friend of individualization, but probably a main competitor of the environment.

\section{Civilization, Culture and Traditional Ethics}

The main area through which individualization can realize its potential is culture. Talking about culture, there are many interpretations and variables in its meaning. The first usage of the term could be ascribed to Cicero [9] who mentioned 'excolere animum' in the sense of cultivating the man's personality. The indication of cultivating the soil is not incidental. Hannah Arendt states [9] that 'culture' leads to Roman word signifying to cultivate, take care, dwell and preserve. As she continuous, the word was originally used in agriculture for cultivating the land for human habitation. In general, culture could be seen as an expression of self-realization of human race and an individual human being. It is the embodiment of the man's intellectual creativity that serves both desires: it expresses abilities as well as it fulfils human needs. Albert Schweitzer [10] differentiates three main areas of culture:

1. Civilization: progress in gaining and applying scientific and technological knowledge.

2. Socialization: progress in understanding habits, symbols, norms, values of particular society as well as human society as a whole.

3. Spiritualization: progress in religious, artistic and moral comprehension.

He finally concludes [10] that culture preferably referrers to 'technology' which he sees as a human control of reason over natural forces; and 'ethics' that is a human control of reason over abundance of opinions. Although both branches support the process of individualization, they do not equally participate in the development of an individual and of the society.

As it can be mentioned, civilization incredibly supported the process of individualization. Ortega y Gasset states [11] that it raised the ordinary man. At this point, individualization is connected with democratization as the access to civilization conveniences. What was appointed only for the elite of society could be now achieved by anybody. Apart from such visible examples like machines, gadgets, home appliances, the significant issue can be seen in economic and emotional comfort, medical care, education, safety, entertainment, free time, travelling. Nowadays, the indivi-dualization means the opportunity to use all achievements of scientific and technological development in order to improve the individual's quality of life.

There are more controversial issues to mention. It is very-well known that since humanity have concentrated on technological and industrial advancement; the ethics did not manage to keep up with the incredible development. As a result, it is not prepared to correspond to actual challenges. There are two theories to clarify this disproportion: As humanity overvalued civilization, culture and ethical matters have been constantly neglected. Other thinkers criticize the exclusivist nature of European traditional conception based on Plato and Christianity. These have been affecting the intellectual field by supporting a monistic system offering only one way of seeing and treating reality. They did not allow new ideas interfering into the system and thus, they did not provide a chance to react to the new situation. Thus, ethics accepts imperatives of environmental or media pretty gradually. Hans Jonas [12] puts the traditional ethics under suspicion stating that its obsolescence lies in:

1. Anthropocentric character: traditional ethics does not deal with nonhuman world. It means its interest covered the relation and acts among people and attitude of the man to God. The only 'out of the man' area of traditional culture's concern was the so called 'techné', which appeared to be ethically neutral. 
2. Immediate impact: the goals of traditional ethics were planned to be of immediate reach, ethics interest was limited to 'here and now'. As Jonas states "the effective range of action was small, the time span of foresight, goal setting and accountability short, control of circumstances limited" [12, p. 5].

3. Objectives: the traditional ethics assumed that "the ethical universe is composed of contemporaries and its horizon to the future is confined the foreseeable span of their lives " $[12$, p. 5].

4. The character of knowledge required for the ability to lead morally justified life was not of a specific nature. It was a merit of ordinary intelligence and not knowledge of scientists and professionals. Moreover, traditional ethics supposed that consequences of human behaviour decisions had non accumulative character.

As a perfection of the traditional ethics can be given e.g. the Gospel According to Mark: Love thy neighbour as thyself [5] or Immanuel Kant's categorical imperative: "Act only according to that maxim whereby you can at the same time will that it should become a universal law without contradiction" [13]. As they considerably contributed to individualization putting emphasis on autonomy in moral judgement, they were bound to the period without the immense civilization growth. As such they need to be supplemented or replaced with new imperatives restrictive to interference of humans. In Jonas's words: "It would mean to seek not only the human good, but also the good of things extrahuman, that is, to extend the recognition of 'ends in themselves' beyond the sphere of man and make the human good include the care for them" [12, p. 8]. For Jonas [12] it means to connect the growth in individualization with the growth of physical reality so that the world would not be only of instrumental value for the man's life but integral and indivisible part of the development of humanity.

\section{Environment and Christian Philosophies}

Although the need for individualization is reaching the climax, the protection of the environment became a must for sustainability of human progress. There is a considerable need of new ethics. As being aware of impossibility to break up the expansive line of civilization all suggestions ground their ideas in connection of individualization with protection of nature; they include the good of man into the good of the environment.

Despite the criticism of traditional conceptions, many followers of Christianity have been trying to reform an opinion of Bible on individualization, science, technology and the man's relation to nature. At first they have acknowledged the phenomenon of a change, growth, development so many years disregarded in the Christian code due to the strong influence of Platonism. Secondly, they accepted the latest scientific achievements. The acknowledgement of Darwin's theory of evolution belongs to the greatest victories by which Roman Catholicism has understood the process of individualization and variability of life. The feature of change and development became a significant part of theories of such prominent thinkers like: Theilhard de Chardin, John F. Haught and Karol Wojtyła. The scholars agree that Bible has always shown a strong potential for an individual: the creation in the 'Image of God', selfrecognition, self-realization, a specific role of each person in care and development of the Universe enriched in experience of a personal relationship to God appeared to be strong motivations to support self. Romano Guardini [14] adds that the process of individualization starts with a ceremony of giving a name to a newborn. Having a name, the infant becomes a full member of the society. In Bible, as soon as God created the Man and Woman, He called them by their names. Adam and Even have been recognized in the $20^{\text {th }}$ out of 31000 verses, unfortunately, after they had been eating fruit from the tree. The both acts (naming and eating) are evident examples of individualization.

The importance of individualization is clearly expressed in spiritual gifts. Bible encourages the man that "there are diversities of gifts, but the same Spirit. There are differences of ministries, but the same Lord. And there are diversities of activities, but it is the same God who works in all. But the manifestation of the Spirit is given to each one for the profit of all" [5, 1 Cor. 12, 4-8]. Unfortunately, the objections pointed out at anthropocentric orientation of the religious concept. Especially if referring to redemption that is reserved to only a human being not considering the physical world at all. Moreover, the division of reality into the temporary 'material world' and the eternal 'World to Come' makes nature insignificant to human interest. Thus, Christianity is sometimes blamed to have neglected non human matters.

John F. Haught, the Roman Catholic theologian with a special interest in issues of science, cosmology, and ecology tries to refute the objections. He [15] provides verses which demonstrate the justifiability of religion to put an effort into natural issues. By reexplanation of their ideas he opens up the minds of atheists as well as believers showing a true interest of Bible to support the reality as a whole. The following verse from The Book of Revelation according to Haught [15] confirms that all things, personal as well as non personal are taken into redemption. "And every creature which is in heaven and on the earth and under the earth and such as are in the sea, and all that are in them, I heard saying: blessing and honour and glory and power be to Him who sits on the throne and to the Lamb, forever and ever [5, Rev. 5, 13]. The words of a great importance could be found in The Old Covenant as well. There is a clear promise: "For I will cause the captives of the land to return as at the first, says the Lord" [5, Jer. 33, 11]. The main idea of the approach offered by Haught 's evolutionary theology is [15] that the cosmos as a whole, similarly to the act of its creation, is appointed to the salvation. There is a great consequence for humanity in this statement: the redemption of people is indivisible from the redemption of the environment and it will not be realized without the participation of the physical reality. Therefore, all activities supporting individualization should be in harmony with natural surroundings.

The ideas with the interest in inclusion of the reality into the redemption are incorporated in philosophy of a French visionary anthropologist Pierre Teihard de Chardin. Being a biologist he does not resist to react to the latest scientific research using the elements of evolution (development), individualization and spir- 
itual growth in order to connect the Christian doctrine with (from the point of Christianity of that time) controversial, Darwin's theory. $\mathrm{He}$ [16] starts with the configuration of the Universe as evolutionary process developing in two directions: inferior (individual) and superior (collective) with the final 'Omega Point' into which both converge. Through individualization, spiritualization and unification the universe unfolds in several evolutionary stages: geogenesis (beginning of Earth), biogenesis (beginning of life), anthropogenesis (beginning of human life), noogenesis (the emergence of the sphere of human thoughts), Christogenesis towards the Omega Point. The important milestones in the evolution are those that show the emergence of consciousness: development of personal beings, consciousness, self-reflexion, cognitive skills, intellect and their representation in human activities like science, religion, art. Thus, the man has a special role in the evolutionary process: "If we wish to settle this question of the 'superiority' of man over the animals, I can only see one way of doing so - to brush resolutely aside all those secondary and equivocal manifestations of inner activity in human behaviour, making straight for the central phenomenon, reflection" [16, p. 164-165]. Naturally, he sees the important stage of evolution in the emergence of the mind and intelligent beings (noogenesis). "Noogenesis rises upwards in us and through us unceasingly. We have pointed to the principle characteristics of that movement: the closer association of the grains of thought; the synthesis of individuals and of nations or races; the need of an autonomous and supreme personal focus to bind elementary personalities together, without deforming them, in an atmosphere of active sympathy" $[16$, p. 257]. The theory might end up in two conclusions:

1. Reality works as an organic and dynamic whole in which humanity creates an important, but still ontologically limited part of the process. Humans are contingent and depend on other constituent. The redemption is an evolutionary process that unifies, spiritualizes and individualizes the world into its final Omega Point.

2. Individualization of the Universe is a process that comes into the existence and is realized via the biological, cultural, technical, scientific, spiritual and intellectual development. Thus, anthropocentric orientation, technology, science and lately also informatization might not have to be elements violating the quality of human life. On the contrary, they are integral parts of evolution.

\section{Vision of Ascetic Society}

However, many thinkers of the $20^{\text {th }}$ century are pretty cautions to praise the extreme technological and scientific growth. They are aware of dangers humanity and their surroundings might be threatened with. The main warnings are aimed at the economic order that is based on consumerism. An economist Victor Lebow stated: "Our enormously productive economy demands that we make consumption our way of life, that we convert the buying and use of goods into rituals, that we seek our spiritual satisfaction and our ego satisfaction in consumption. We need things consumed, burned up, worn out, replaced and discarded at an ever-increasing rate" $[17, \S 19]$.

Not only Lebow explained the consumerism, but he also connected the individualization and excessive buying. In the period of fragmentation, disintegration of values, loss of identity, loose family and cultural roots people are desperately searching for something what would support their feeling of belonging somewhere and being somebody of a particular significance. They concentrate on things that are offered and are said to emphasise their value. The latest fashion including portable novelties in electronic industry, luxury goods being on display, ability to replace an old product by a new model, travelling, cosmetic industry are creators of people's personalities. It is mainly the luxury in various ways which is a way of individualization in Postmodernism. However, consumerism devours its own children. Hans Jonas says that if we want to preserve the world and the same living conditions for next generations we cannot afford such lifestyle. He asserts: "happiness of present or proximate generations would be bought by unhappiness and or even non existence of later once" [12, p. 11] A solution lies: firstly, in reduction of consumption and secondly, as science has already caused irreversible damage to the nature, in sensible control of the scientific research. The supreme imperative is preservation of human life. Therefore, he updates Kant's categorical imperative: "Act so the effects of your action are compatible with permanence of genuine human life, or negatively, Act, so that the effects of your action are not destructive of the future possibility of such life" [12, p.11]. Thus, neither individualization nor civilization is entitled to menace the continuance of the life on the Earth. The objective of the new future-oriented ethics is something which has not come into its existence yet: next generations.

His ethics can be compared to Weizsacker's suggestion. In the title of his books he asks [18]: 'Are we going towards ascetic culture?' There, he offers [18] a radical idea of culture that consciously and voluntarily surrenders on commodities that are accessible in order to handle reasonably with civilization. His idea of individualization lies in virtues of moderation, temperance, self control, asceticism, compassion, sensibility. They are issues of individual freedom, individual decision and individual awareness by which the man proves himself to be a responsible citizen of the $21^{\text {st }}$ century civilization. According to Weizsacker [18], it is the only way how humanity can prevent exhaustion of material sources as well as emotional and moral vacuum. As an opposite to the solution offered by the Christian scholars we can mention Slovak thinker Vasil Gluchman [19] whose conception appears to be more realistic while introducing his solution of 'sensible egoism'. According to him humanity will have to accept limitation of consumption, but not voluntarily, but as an entire necessity. However, the theory supports the anthropocentrism because it focuses on the features of self preservation rather than on an ethical choice.

The attitudes described above are essential supplements of ecocentrism [2] the nature-centred system of values, that would deny humans as the sole bearers of intrinsic value. It also provides a guarantee of an inherent value of nature in its own right. This approach puts emphasis on balance and mutual dependence between 
humanity and the environment as it had been stated in the book of Genesis. Despite the qualities (logos, free will, intellect, daimonion) the man was endowed by his Creator, he seems not to be mature enough to be a centre of the Universe in order to take care of the Earth. The metaphysical rebellion [20] as well as demystification of nature proves to be ambiguous processes. Thus, individualization in moral field that enables each man to decide and act autonomously has not been completed yet. Apparently, it still needs a leadership of a code protecting fragile parts of reality.

\section{Conclusion}

The growth of civilization is closely connected with the quality of life and more opportunities for an individual. Despite all bene- fits humanity need to confront many challenges among which the most serious is environmental damage. There are more aspects why the man feels entitled to interfere into the environment: anthropocentrism of culture, traditional ethics that does not correspond with requirements of scientific and technocratic age, attitude to nature that states its instrumental character towards human life, invasive intervention of civilization into the balance of nature. There have been more solutions offered. The new ethics requires including the goods of nature into the goods of human life, replacement of consumerism with voluntarily asceticism, sensible control of scientific research. Human thinking should shift its orientation from 'human centred' to 'nature centred' in order to protect not only contemporary people but preferably to preserve the existence of next generations.

\section{References}

[1] Webster's II New College Dictionary, USA, Boston, Haughton Mifflin Company, ISBN 0-395-96214-5, 2001

[2] BECKMAN, S.; KILBOURN, W.E. at al.: Anthropocentrism, Value System, and Environmental Attitude. A multi national Comparison, http://www.uc3m.es/portal/page/portal/grupos_investigacion/sociologia_cambio_climatico/Pardo\%20-\%20Anthropocentrism\%20 Environmental\%20Values\%20(ENG).pdf, 1977

[3] PLATO: Apology: Socrates'defence, < http://classics.mit.edu/Plato/apology.html>

[4] ARISTOTLE: The Nicomachean Ethics, <http://www.constitution.org/ari/ethic_00.htm>

[5] The Holy Bible, The New King James Version, New York, American Bible Society, 1990

[6] JOHN PAUL II.: Fides et Ratio, < http://www.vatican.va/edocs/ENG0216/_P2.HTM>, 1988

[7] The Rule: The third order secular of our holy father Saint Francis, USA, North America Old Roman Catholic Church, 2010

[8] BACON, F.: The New Organon, UK, Cambridge University Press, ISBN 0521 563992, 2000

[9] ARENDT, H.: Between Past and Future, USA, Penguin Books, ISBN 0140186506, 1993

[10] SCHWEITZER, A.: Culture and ethics (in Slovak), Bratislava, Slovensky spisovatel, 1986

[11] GASSET, J.O.: Revolt of the Masses, New York: London, W.W Norton \& Company, ISBN 039331095 7, 1993

[12] JONAS, H.: The Imperative of Responsibility, USA, University of Chicago Press, ISBN 022640597 4, 1985

[13] KANT, I.: Critique of Practical Reason, London: New York, Longmans, Green and Co., 1898

[14] GUARDINI, R.: To accept yourself (in Slovak), Trnava, Dobra kniha, ISBN 807141296 1, 2000

[15] HAUGHT, J.F.: God after Darwin. A theology of Evolution, Boulder, Westview Press, 2000

[16] TEILHARD De CHARDIN, P. The phenomenon of Man, USA, Parennial, ISBN 006090495 X, 2002

[17] LEBOW, V.: Journal of Retailing. 〈http://hundredgoals.files.wordpress.com/2009/05/journal-of-retailing.pdf〉, 1955

[18] WEIZSACKER, C. F.: Are We Going Towards Ascetic Culture? (in Slovak), Praha, Archa, ISBN 807115091 6,1995

[19] GLUCHMAN, V.: The Ethics of Social Consequences (in Slovak), Presov, FF PU, ISBN 8088859 034, 1999

[20] KLECKOVA, M.: On Some Aspects of Revolution from the Perspective of the Christian Personalism of N.A. Berdyaev, In: J. of Interdisciplinary Philology, Vol. 1, Faculty of Humanities, University of Zilina, 2011, ISSN 338-0591. 